\title{
Sanitization During and After COVID-19 Pandemic: A Short Review
}

\author{
Majid Hassan Khan ${ }^{1}\left[\right.$ D Harekrishna Yadav ${ }^{2}$
}

Received: 17 June 2020 / Accepted: 12 October 2020 / Published online: 1 November 2020

(C) Indian National Academy of Engineering 2020

\begin{abstract}
Sanitization is a preventive and strategic method to contain the spread of SARS-CoV2. Since there is no foolproof method to tackle the present COVID-19 pandemic, sanitization has a central role to play. The present article briefly reviews various methods of sanitization for individuals, surfaces and ambience. The article reviews different approaches toward sanitization and examines the historicity of the methods employed.
\end{abstract}

Keywords Sanitization $\cdot$ COVID-19 $\cdot$ Fomites $\cdot$ Mask sanitizaton $\cdot$ Hand sanitization $\cdot$ Surface treatment

\section{Introduction}

On 11 February 2020, WHO announced the name of the new disease from the virus of Coronaviridae family in the Nidovirales order known as the "COVID-19". The virus is named corona (Latin name crown) due to the presence of the crown-like structure on its outer surface (Shereen et al. 2020). The symptoms of COVID-19 may include fever, coughing, shortness of breath, sure throat, runny nose, etc. Chamola et al. (2020) list the common symptoms. There are three different routes of the transmission of COVID19 viruses from the contagious person to a healthy person. These are the direct route, indirect contact, and airborne transmission (Fig. 1). Figure 1 lists the route of transmission and possible sanitization employed.The direct mode transmission implies the transfers of virus between infected and susceptible hosts via person-to-person contact. While the indirect mode of transmission indicates the transmission of the virus from the objects used by the infected person or the immediate environment of the infected individual (WHO 2020a; Ong et al. 2020). The airborne transmission of the

Majid Hassan Khan

mhkhaniitb@gmail.com

Harekrishna Yadav

krishnpme@iiti.ac.in

1 Department of Mechanical Engineering, Indian Institute of Technology Bombay, Mumbai 400076, India

2 Discipline of Mechanical Engineering, Indian Institute of Technology Indore, Simrol 453552, India virus occurs through the droplet spray formed during natural human exhalation flows (Asadi et al. 2020).

Ordinary breathing and speech generate a large amount of potentially infectious aerosols (Asadi et al. 2020; Duguid 1946; Papineni and Rosenthal 1997). The particle generated during human exhalation flows such as coughing, sneezing, and breathing are two-phase buoyant jet emerging from the mouth and/or nose (Mittal et al. 2020; Tang et al. 2013). Asadi et al. (2019) reported that the rate of particle emission during normal human speech is up to 50 particles/s. Further, the velocity, number, and size distribution of the infectious droplet play an important role in virus transmission. The number of particles and their velocity is a function of the different modes of breathing, speech loudness, sneezing, and coughing (Mittal et al. 2020; Asadi et al. 2019). Natural human breathing and talking produce a jet velocity of $4.5 \mathrm{~m} / \mathrm{s}$ (Tang et al. 2013). Han et al. (2013) determined the size distribution of sneeze droplets exhaled immediately at the mouth and observed that a sneeze produces an order of $10^{4}$ droplets moving with an average velocity of $20 \mathrm{~m} / \mathrm{s}$. Coughing produces 10-100 times lesser droplets than sneezing. The cough droplets travel with a lesser velocity of approximately $10 \mathrm{~m} / \mathrm{s}$ (Asadi et al. 2019; Mittal et al. 2020). The average diameter of a coronavirus is $65-125 \mathrm{~nm}$ (Shereen et al. 2020). The respiratory droplets are in the size of $>5-10 \mu \mathrm{m}$ (WHO 2020c), i.e., one small viral droplet carrier can hold around 77 Coronaviruses. Further, the rate of particle emerging during human exhalation flows would be around $77 \times 50 \approx 3850$ viruses/s. These airborne viruses contaminate the ambience and settle on surfaces. Huang et al. (2020) explain how fomites formed from deposited 
Fig. 1 Routes of COVID 19 transmission and their mode of sanitization

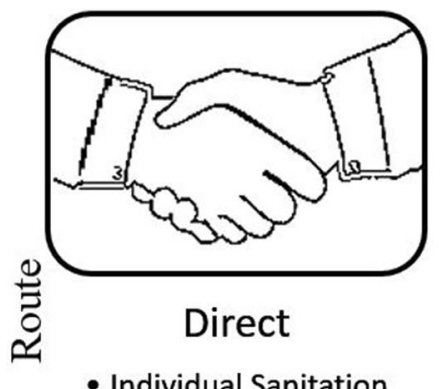

- Individual Sanitation

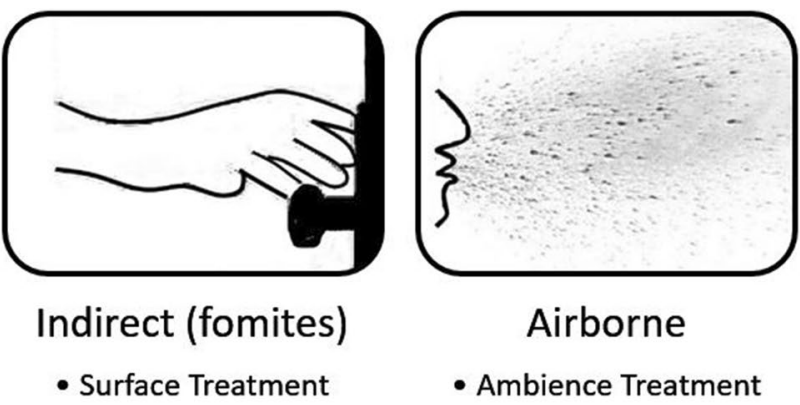

Categories of sanitization droplets are potentially infectious. The pathways for infection explained by Huang et al. (2020) creates a need for an understanding of the process of reducing the fomites and virus laden airborne droplets to break the spread of COVID19. Diwan et al. (2020) simulated dry cough and showed a drop in temperataure of cough-fluid along with a lateral spread of flow due to turbulent entrainment. Dbouk and Drikakis (2020) used multiphase computational fluid dynamics to explain the airborne droplet transmission of viruses. They examined ambience contamination at different wind speeds by taking into account humidity, dispersion, phase change, and droplet interactions. Bhardwaj and Agrawal (2020) analysed the drying time of respiratory droplets from COVID19 infected subjects. Their work explains the relationship of evaporative rate of a droplet and the spread of COVID-19. This indirectly hints at the capacity of the infected surface in spreading the virus. Since salivary droplets take longer time to evaporate than water droplets - the works of Bhardwaj and Agrawal (2020) and Dbouk and Drikakis (2020) caution about the viral spread from droplet bearing ambience and surfaces.

At present, there are no vaccines available and it is of utmost importance to curb the deadly coronavirus spread by prevention and protection itself. Although social distancing has contained the spread of virus as a passive mechanism, a pragmatic look at the method to contain the virus by disinfecting and deactivating it is necessary. Almost all areas of research have come forward on a war footing and contributed towards the know-how to mitigate the spread and restore a regular life. By the time, vaccine is developed and distributed there is a need to protect ourselves and prevent the virus from further harming people. Sanitization has so far played an important role in containing the spread and in restoring everyday life albeit on a smaller scale. The mechanism involved in sanitization uses either one or both of these steps: (i) mechanical or thermal treatment and/or (ii) use of virucidal/anti-microbial agents to decontaminate the body part, object or surfaces. The overall sanitizing action is to weaken the virus by depleting the lipid membrane using a disinfectant and remove it from the surface.
We briefly review the existing measures of sanitizing individuals, objects and spaces to inhibit the virus's life and to stop/break the spread of viruses. Figure 1 explains the transmission routes along with the categories of sanitization. Figure 2 gives a detailed list of methods used for sanitization and disinfection of COVID-19 infected people, objects and spaces.

In the following section, we review the different categories of sanitization and stress on the developments done so far. We propose the possible methods of improvement and acknowledge the harm of obsessive use of any particular sanitization process.

\section{Individual Sanitization}

Sanitization is a pragmatic approach to tackle the issues associated with infection and contamination. The crucial requirement of sanitization in recent pandemic paves an area of active research to cater to any health crisis in the future spread of unpredictable disease(s). Sanitization as an area of interdisciplinary research needs a central focus in the longer run. One should address the community level spread of disease at individual scales before handling it on a social scale. Individual sanitization helps in reducing the mammoth spread of virus and prevents it from taking a colossal shape for the society as a whole. Crowd is made of individuals who are a part of a crowd, so it is incumbent on every individual to act for the benefit of the larger group. Masks and etiquettes of sneezing have largely been promoted since the outbreak of a pandemic. Different regulatory bodies have also stressed the central role of hand sanitization.

\section{Hand Sanitization}

For the disinfection of the hand, alcohol-based hand rub or soap with water are preferred (WHO 2020b). The alcoholbased hand rubs are mainly formulated with ethanol, propan-2-ol or propan-1-ol. Some of the hand sanitizers also contain additional chemicals such as triclosan, chlorhexidine 
Fig. 2 Categories of sanitization to contain the spread of COVID 19
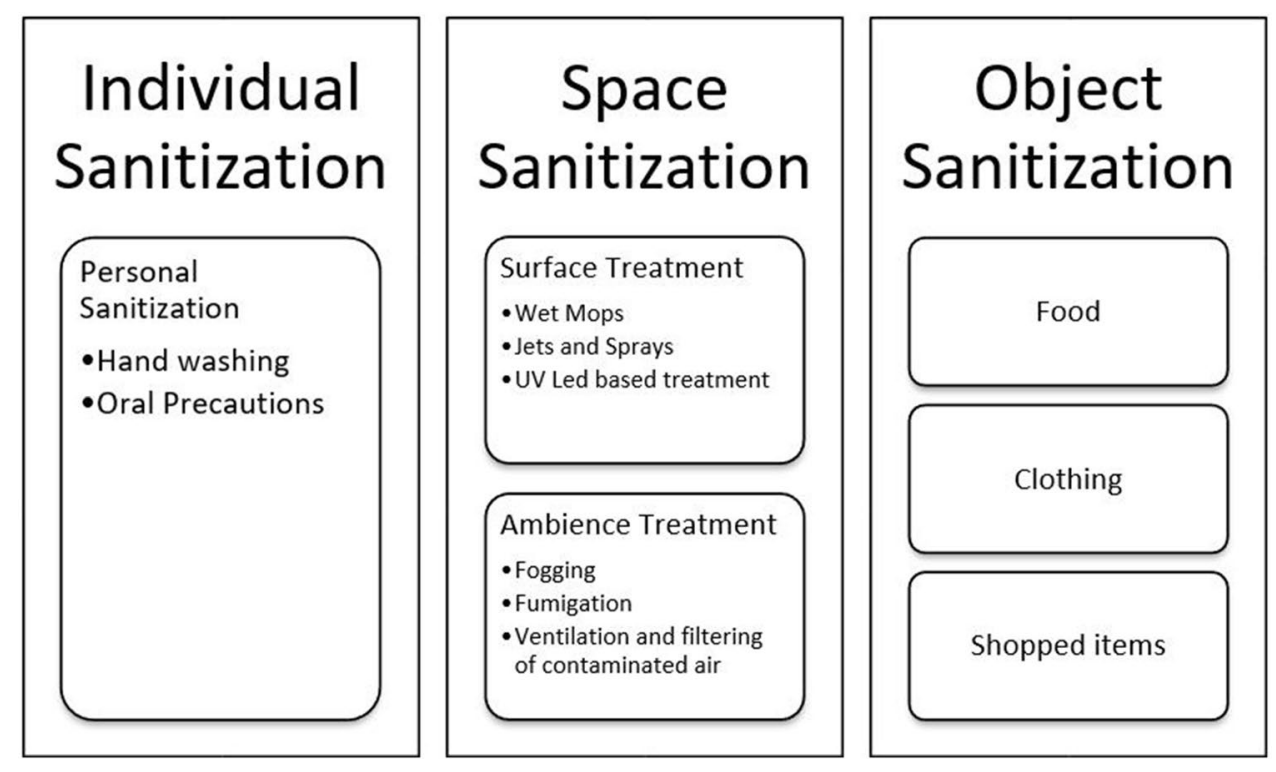

digluconate, benzalkonium chloride, polyhexanide, hydrogen peroxide, DDAC, peracetic acid, and/or octenidine dihydrochloride (Kampf 2018). Alcohol based hand rubs inactivate the virus (Kratzel et al. 2020). Hand wash containing $62-70 \%$ alcohol has been found to be effective in inactivating avian flu influenza A H5NI virus (Bondi et al. 2007). Pradhan et al. (2020) suggests some commercially available sanitizers and provides details about their chemical constituents. However, there are the localities lacking alcohol-based sanitizer or water and soap facilities. It is the usual practice of using ash, mud, and or rubbing of hand on the ground in rural areas of the Indian subcontinent (Hoque and Briend 1991). A survey in Kolkata India reported that $41 \%$ of slum residents and $26 \%$ of rural villagers use ash for hand washing (Anuradha et al. 1999; Ray et al. 2006).

Mathur (2011) explains the importance of hand hygiene and elaborates the methods for hand washing. Mathur (2011) has recommended rinsing of hand with water, lathering with soap and then washing with running water followed by drying with single use towel or hot air blower. Miller et al. (2011) studied the effects of wash time, friction and soap on hand sanitization and concluded that washing ones hand running water with friction for $20 \mathrm{~s}$ is effective with marginal improvement on using soap. In the process of hand sanitization, mechanical removal is followed by disinfection using sanitizing agents. The sanitizing agents like alcohol and soap inactivate the virus by destroying the lipid membrane and exposing the intracellular content (Jing et al. 2020). Jing et al. (2020) have listed five different types of hand sanitizers: (i) gel, (ii) foam, (iii) cream, (iv) spray and (v) wipes. They explain the mechanism of inactivation of the viruses and bacteria using sanitizers and highlight the adverse effect of excessive use on the epidermis. Contact dermatitis and deterioration of lipid barriers of the skin are serious concern of excessive use of sanitizers. Emami et al. (2020) too explains the problematic effects of non-standard formulas for alcohol based hand sanitizers in causing skin dryness and irritation. Overuse of surfactants and soaps too harm the epidermis by negatively affecting the lipids, proteins and keratin composition.

Hoque and Briend (1991) analyse the efficacy of different hand washing using ash, soap, mud, or plain water. They found that mud and ash are even more efficient than soap. In addition, there are the studies suggesting that the soil and ash may be used as hand disinfectants (Pittet et al. 2009; WHO 2020b). Bloomfield and Nath (2009) reviews the efficacy of mud and ash in removing the pathogens. Hand hygiene is a product of proper mechanism of hand washing, which include removal of microbes using soap or other materials, rubbing to remove dislodge the microbes, use of clean water for rinsing and drying. The efficacy of mud is directly dependent on the cleanness and dryness of the soil used for washing and the mechanical action of rubbing during hand washing. The obvious drawbacks for mud is that contaminated mud can transmit many other forms of disease.

Baker et al. (2014) tested the role of $\mathrm{pH}$ value of ash and water slurry and found that preparing the ash and water slurries increases the $\mathrm{pH}$ value, which inactivates the pathogens. Alternate non-alcohol based hand sanitization is important for patients undergoing alcohol treatment. De Sousa (2020) presented a case of 43 years old (on abstinence using $250 \mathrm{mg}$ of disulfiram per day) who experienced Disulfiram Ethanol Reaction (DER) due to excessive exposure to alcohol based sanitizers. Although the allergic reaction was due to inhaled alcohol, the medical case hints at the damage excessive use can cause especially in a confined and poorly ventilated space (Huynh-Delerme et al. 2012; Brewer and Streel 2020). Hand sanitization and other modes of sanitization that use 
surfactants and disinfectants are bound to create a sludge of surfactant overload on the water bodies. Earlier work by Lewis (1991) has reviewed the effect of surfactant toxicity on aquatic animals. Xue et al. (2012) investigated the toxic effect of surfactant and disinfectant on rats and explained how the lungs and kidneys are vulnerable organs.

\section{Oral Precautions}

With masks, being a mandatory precaution during this pandemic active sanitization of inspired and expired air is required. Huang et al. (2020) suggested chemical modulation of respiratory exhales to impregnate the virion-laden droplets with anti-viral/sanitizing molecules. Panda et al. (2020) propose a modified anatomical facemask that clubs heat and moisture exchanger bacterial/viral filter $(\mathrm{HME}+\mathrm{bv})$ with the anatomical face mask. Anitviral and virucidal tendencies of fatty acids and lipids against viruses (Hilmarson et al. 2007) have been an area of research which seems to provide tangible protective measures against COVID-19 (Park and Gallagher 2017; Ghaffari et al. 2020). Dayrit and Newport (2020) have suggested the antiviral characteristic of Lauric acid found in coconut oil as a safeguard against the virus. Ministry of AYUSH, Government of India (2020), suggests nasal applications of coconut oil as a protective measure. Although the claim is traditional and untested, the science in support of antiviral nature of fatty oils can be used as a prop of AYUSH's suggestion as an added protective measure along with facemasks. The traditional practice of oil pulling too can be used alongside masks to capitalise on the virucidal ability of fatty acid.

Alongside the proposed active sanitization of breath flows regular cleaning and disinfection of masks is important. Cloth facemasks can be detergent washed and cleaned. Special masks need care and disinfection using one or many methods listed under different headings below. N95 masks have found wide use as medical masks and they need regular disinfection and decontamination. Mackenzie (2020) proposes the following methods to disinfect and reuse N95 masks: (i) ultraviolet irradiation, (ii) fumigation, (iii) hot water heating, (iv) steaming and (v) baking. Microwave, alcohol and bleach destroys the effectiveness of N95 masks. Saini et al. (2020) has developed a vaporised hydrogen peroxide based decontamination method for PPE, coveralls and N-95 masks. It has been shown using scanning electron microscopy (SEM) that the treatment alters neither the permeability nor the fibre thickness. Li et al. (2020a, b) proposed steam treatment of surgical and N95 masks. Ji et al. (2020) lists the treatment level required to get acceptable filtration and antimicrobial performance for various methods of decontamination of masks. Vaporised hydrogen peroxide requires around $10-30 \mathrm{~min}$, microwave generated steam (for microwave models: 1100-1250 W) needs $2 \mathrm{~min}$, microwave steam bags (for microwave model: $1100 \mathrm{~W}$ with $60 \mathrm{~mL}$ tap water in the bags) needs $90 \mathrm{~s}$ and moist heat incubation needs treatment for $15-30 \mathrm{~min}$ at $60^{\circ} \mathrm{C}$. Rubio-Romero et al. (2020) too have reported vaporised hydrogen peroxide, ultraviolet radiation, moist and dry heat to be effective. Zulauf et al. (2020) have proposed use of microwave-generated steam to decontaminate N95 masks using commonly available materials like glass container, commercial mesh bag, rubber band a $1100 \mathrm{~W}$ commercially available microwave. They have established that the process of decontamination retains the respirator fit and function.

The methods established for sanitizing facemasks, need an optimal operation. Over exposure of any of the abovementioned processes, will deteriorate the filtration function and fitness of the masks.

\section{Space Sanitization}

Sanitization for surfaces and for ambience can tackle the spread of COVID-19 virus in professional and domestic spaces. The following sections briefly review the required sanitization process.

\section{Surface Treatment}

A spray of respiratory droplets from an infected individual may also land on surfaces where the virus could remain viable and can serve as a source of transmission (WHO 2020a; b, c). The study by Kampf et al. (2020) shows that viruses can persist on surfaces from $2 \mathrm{~h}$ to 9 days. The survival time depends on the type of surface, relative humidity, temperature, and the strain of the virus (WHO 2020b; Dbouk and Drikakis 2020). Doremalen et al. (2020) determined the stability of the COVID-19 virus and their decay rate on different surfaces (plastics, stainless steel, copper, and cardboard). They reported that viruses on plastics and stainless surfaces could be viable for up to $72 \mathrm{~h}$. While, on copper and cardboard surface, the virus is less stable and can survive only for $4 \mathrm{~h}$ and $24 \mathrm{~h}$, respectively. Furthermore, the same study reported that the virus titer reduces with time. Kampf et al. (2020) have reported the persistence of various stains of viruses on a different type of intimate surface. These surfaces infected with viruses are fomites and provide the indirect route of transmission.

The contaminated surfaces can be decontaminated within a minute using common surface disinfection procedures with $62-71 \%$ ethanol, $0.5 \%$ hydrogen peroxide, or $0.1 \%$ sodium hypochlorite (WHO 2020b; Kampf et al. 2020). Further, the same study explains that the degree of effectiveness of all the surface disinfect is dependent on their concentration and exposure time. Therefore, it is imperative to clean the surface with soap and water before applying any surface 
disinfectant. In a review on intervention to prevent COVID19 Pradhan et al. (2020), provide the 'list N' based disinfectants as per the United States Environmental Protection Agency (USEPA). Although the disinfectants have not been specifically tested for COVID-19, USEPA expects them to be effective based on their demonstrated performance against other hard to kill viruses. Doremalen et al. (2020) reported that the half-life of SARs-COV 2 on stainless steel was $5.6 \mathrm{~h}$ and it was $6.8 \mathrm{~h}$ on plastic. The half-life is lesser on copper surfaces, indicating that in the long run copperization and copper plating to be a safer alternative for metal surfaces of daily use. The following methods can be adopted for sanitizing surfaces: (i) mops, (ii) sprays and (iii) UV Led based treatment.

\section{Wet Mops}

Chemical disinfectants applied to floors, doorknobs, table surfaces and surfaces in domestic and office use can be used to deactivate the corona spread. The measure to contain the spread of virus needs application of a fluid layer that has disinfectant added to it. One can wash the surfaces with water, soap and/or USEPA identified disinfectants. The film formed after washing would be thicker because water spreads and attains thickness according to the capillary length (a $=\sqrt{ }(\gamma / \rho g)$ where $\gamma$ is surface tension and $\rho$ is the density of water), since beyond this the gravity effect helps in spreading the fluid over the surface (De Gennes et al. 2013). For water air interface, the capillary length is $2.71 \mathrm{~mm}$, which is much larger than the size of one virus $(\sim \mathrm{nm})$. One can use mopping to uniformly spread the water-disinfectant fluid mixture. Using a mop one can shear the fluid in a thin film $(\sim \mu \mathrm{m})$; this will have dual effect of reducing the envelope of water around the corona virus and at the same time create a film of disinfectant on the surface being sanitised. The process will even lead to an increase in the evaporation rate since the fluid film will evaporate faster than the fluid layer. So mopping is an efficient sanitization mechanism. Andersen et al. (2009) compared the effectiveness of (i) dry, (ii) spray, (iii) moist and (iv) wet mopping, in removing organic materials from hospital room floors. Wet and moist mopping out performed all other methods. Wet mops moistened with disinfectants perform the dual role of mechanical removal and disinfection due to inactivation of the virus. Untreated sanitizing fluid and wet mops can be a counterproductive method of sanitization, since the used mop will become an active carrier of pathogens. Westwood et al. (1971) recommended regular laundering and drying of wet mops for proper decontamination. The process also helps avoid overuse of disinfectants for sanitization. Overuse of disinfectants can harm the environment, besides having other drawbacks mentioned earlier in section "Hand Sanitization".

\section{Jets and Sprays}

Surfaces that are not accessible for mopping can be cleaned using jets and sprays. An aerosol created using disinfectant and the base fluid combination can be used to spray the inaccessible areas. The nanometer-sized corona embedded in micron sized cough droplets can easily reach inaccessible areas when an infected person coughs or sneezes. So a proper use of spray and jet should be employed to disinfect such inaccessible surfaces. Misters and wide-angle nozzles used in aeroponics can be employed for spray formation. Still, the spread of the sessile droplets on the surface will heavily depend on the coagulation of droplets and the curvature of the surface. Schneiderman and Cartee (2020) suggest a two-step method of disinfection: cleaning the surface followed by spray. Better disinfection is obtained when large dust particles on the surfaces are removed using wipes or detergent followed by spraying of EPA-registered disinfectant. Cadnum et al. (2015) have demonstrated the use of $1.4 \%$ improved hydrogen peroxide spray for soft surfaces and inaccessible parts to reduce contamination. The process does not need any mechanical wiping.

\section{UV LED-Based Treatment}

As explained earlier for disinfecting N95 masks (Mackenzie 2020) ultraviolent irradiation is an option to disinfect and decontaminate surfaces and inanimate objects, like clothes, utensils, medical instruments. Tseng and Li (2007) demonstrated the susceptibility of SARS-CoV at various relative humidity. The effect of ultraviolet germicidal irradiation to inactivate surface viruses were demonstrated. Kim and Kang (2018) measured the effectiveness of UVC LED in inactivating viruses. Moore in an article in ieeespectrum (dated 16th April 2020) explains how UVC LED makers claim to eliminate corona virus using a $30 \mathrm{~s}$ dose from a $3 \mathrm{~cm}$ distance. Although the UVC LEDs are useful in decontaminating influenza viruses including the recent novel coronavirus, their effectiveness decreases with increasing relative humidity (Tseng and Li 2007; McDevitt et al. 2012).

\section{Ambience Treatment}

The contagiousness of COVID-19 is acute due to its long half-life and airborne spread. Exhaled breathe from infected person, cough, sneeze, etc., aid in infecting the air (Dbouk and Drikakis 2020). Li et al. (2020a, b) used airflow simulations to establish the evidence of probable aerosol transmission of SARS-CoV-2. This vulnerability of an ambience and associated likelihood of transmission of the virus by airborne route creates the necessity for ambience sanitization. On a colony or street level, infected areas and containment zone become difficult regions for human involved sanitization. 
The use of technology especially the newly evolving area of UAV is an apt alternative. Agriculture spraying drones can be used for the sanitization of public places (Fig. 3). It can carry upto16 litres spraying tank and can cover a 100,000 square meter area (Singla 2020). Smaller ambience can be sanitised by (i) fogging, (ii) fumigation and (iii) ventilation and filtering of contaminated air. Treatment of an area using fogging and fumigation need proper ventilation as recommended in the study of the aerodynamics of SARS-CoV-2 in two Wuhan hospitals (Liu et al. 2020). Similar environmental contamination has been reported in two healthcare settings of South Korea (Ryu et al. 2020). USEPA does not recommend use of chemical disinfectants for fumigation and fogging unless the product label specifically permits such practice (FAQ-USEPA 2020).

\section{Fumigation}

Fumigants have been traditionally employed for a long time for their germicidal tendencies (Chen et al. 2013). Appendix 3 of an edited volume on Anthrax for humans and animals (Turnbull 2008) explains the sporicidal tendencies of fumigants and provides details about the methods, disinfectants and safety measures for fumigation. Numerous research in the past have focused on the virucidal tendencies of fumigants.

Fumigation using ozone gas (Tanaka et al. 2009) and chlorine dioxide (Miura and Shibata 2010) have been found to be effective for the influenza virus. Human noroviruses (HuNoV) which also transmits through human contact and contaminated surfaces can be disinfected using hydrogen

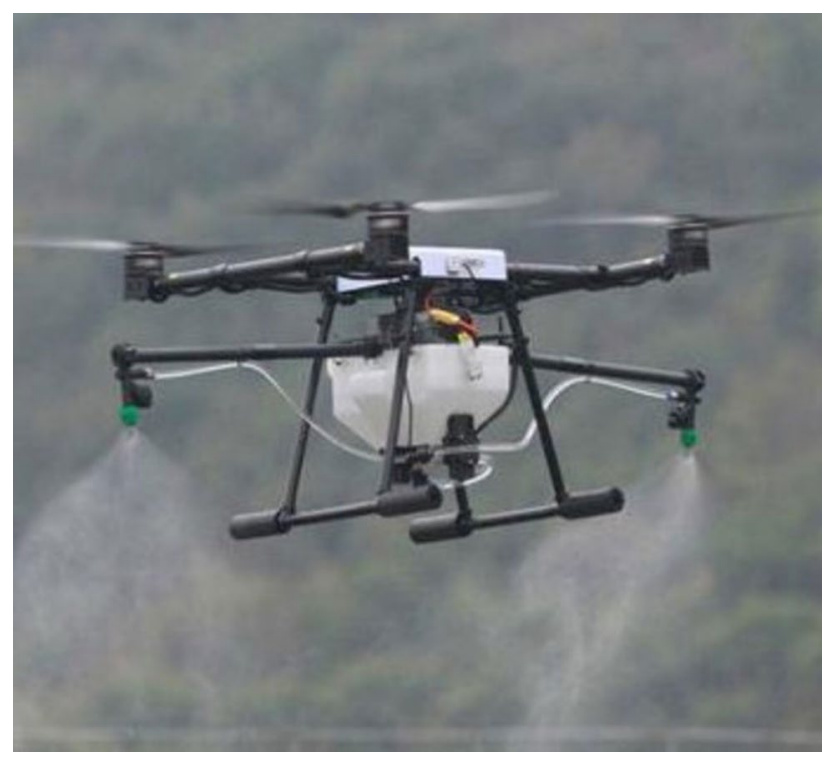

Fig. 3 Application of drones for sanitization during COVID-19 pandemic (Singla 2020) peroxide fumigant (Zonta et al. 2016). Cha et al. (2016) tested the use of paraformaldehyde for highly pathogenic avian influenza (HPAI) virus as a fumigant to decontaminate surfaces in laboratory settings. Meszaros et al. (2005) recommends use of vaporised hydrogen peroxide (VHP) as a safer alternative than formaldehyde especially to decontaminate enclosed areas. McDonnell et al. (2007) used (i) dehumidification, (ii) conditioning, (iii) disinfection and (iv) aeration and ventilation as four stages of fumigation using VHP units. As mentioned earlier, Mackenzie (2020) explains the use of hydrogen peroxide as a fumigant to disinfect N95 masks.

Since most of the fumigants proposed earlier are for closed room disinfection, fluid dynamical investigation can help model and design an efficient fumigation unit. Chayaprasert et al. (2010) provides a CFD based modelling approach for structural fumigation. Open-air fumigation of bigger areas are risk prone due to tangential toxicity of the disinfectants employed. If there is an alternate, safer and non-toxic fumigant, a full air fumigation can be employed using the concept proposed by Xu et al. (1997). Any fumigation method employs chemical disinfectant and has potential risk for people around. It is advisable to properly ventilate the ambience and renew the air before human use.

\section{Fogging}

The fogging device spray disinfectant mist of various particle sizes and disperse into the air as aerosol (fog). It can be used for both surface and ambience sanitization. The effectiveness of the generator depends on the particle size, humidity, and contact time of disinfectant (Burfoot et al. 1999). Hoffmann et al. (2008) reported that the droplet size of the aerosol is one of the most significant factors that decide the success of spraying insecticide. The fogging technique is frequently used in agriculture for the application of pesticide (WHO 2003), mosquito control (Rose 2001), and the food industry (Burfoot et al. 1999). In addition, fogging is used for generating the seeding particles (sizes $0.2-5 \mu \mathrm{m}$ ) application in particle image velocimetry technique (Presser et al. 2006; Anufriev et al. 2013; van Hout et al. 2018).

The fogging technique is a rapid approach to control the outbreak of the infectious disease in epidemic situations and to control flying insect pests or vectors (WHO 2003). This technique requires the minimum exposure time to kill the insect or disease's virus (Chung et al. 2001). However, it is an expensive method and may not be perfect for all situations (WHO 2003). Lal et al. (2020) suggested that sanitization of surface of OPD rooms through the fogging technique is not an effective method during the COVID-19 epidemic, as it does not properly clean the affected surface. During COVID-19 epidemic, it is used for the decontamination of the suspected area, which cannot be properly cleaned with 
mopping. According to Hoffmann et al. (2008), there are two types of ground or aerial sprayers: thermal and cold fog generators. Thermal fog requires a carrier fluid generally oil to dilute the concentration of insecticide. A hot gas heats the oil decreasing its viscosity which emerges from the fog generator's nozzle as a vapour (Fig. 4a). Whereas spray from the cold fog is generated by mechanical means without using any heat source (WHO 2003) (Fig. 4b). The selection of the type of fog generator depends on the applications, such as type of space and accessibility of the target area (WHO 2003). The size of the aerosol coming out from the nozzle should be in the range of $10-30 \mu \mathrm{m}$, which can remain in the atmosphere for a longer time (Himel 1971; WHO 2003; Hoffmann et al. 2008). Even with the limitations attached to fogging it is an alternative to disinfect closed ambience using approved disinfectants (FAQ-USEPA 2020).

\section{Ventilation and Filtering Contaminated Air}

Understanding the flow pattern in a building is an important necessity to manage the quality of indoor airs and to have an efficient exchange of air with the surroundings. The air flow inside, stratification and buoyancy induced due to temperature define the driving mechanism for natural ventilation (Linden 1999). The case of infection due to aerosol transmitted SARS-CoV2 in a restaurant ( $\mathrm{Li}$ et al. 2020a, b) and two Wuhan hospitals (Liu et al. 2020) due to poor ventilation necessitate a need of proper ventilation with adequate air filtering. Villafruela et al. (2013) employed computational fluid dynamics to propose a design of ventilation system for isolation rooms. The relative location of air droplets and outlet was analysed. The overall study accounted for renewal of air, risk of airborne transmission and removal of contaminant. Novoselac and Srebric (2003) reported that the choice of ventilation strategy defined the correlations between the removal of contaminant and air-exchange efficiency. Singh and Tripathi (2020) propose experimental and computational fluid dynamics models to establish an understanding for improved ventilation design for hospitals, isolation rooms and enclosed spaces. Better ventilation when combined with efficient filtering of air will help sanitize and improve the quality of air in living rooms and isolation rooms. USEPA too recommends the use of proper ventilation and suggests the use of air purifiers and at the same time stresses their effectiveness only- "when used along with other best practices recommended by the Centers for Disease Control and Prevention". Ultraviolet C treatment of air is another technique that can be used to decontaminate ambience. The characteristics employed is similar to the method stated earlier for surface treatment. McDevitt et al. (2012) proposed use of UV-C for air disinfection in public buildings and contain the spread of influenza virus in the air.

In addition to the sanitization processes listed above, public places have seen sprouting of sanitization chambers or disinfection tunnel. Although this is not a preferred public space sanitization mode as explained by Biswal et al. (2020). The disinfection tunnel can be installed at crowded public places such as shopping malls, vegetable markets, hospitals, industry, etc. The entry of the people to the common place should be restricted through the tunnel only. The design of tunnel in such a way that it even allows a man ridded on two-wheelers. There are two type of tunnel has been developed (Biswal et al. 2020): (i) a static type tunnel in which person stays inside the tunnel for 10-15 min and a disinfectant sprayed from the nozzle, (ii) a dynamic type of disinfectant tunnel where individuals walk in $16-25 \mathrm{ft}$

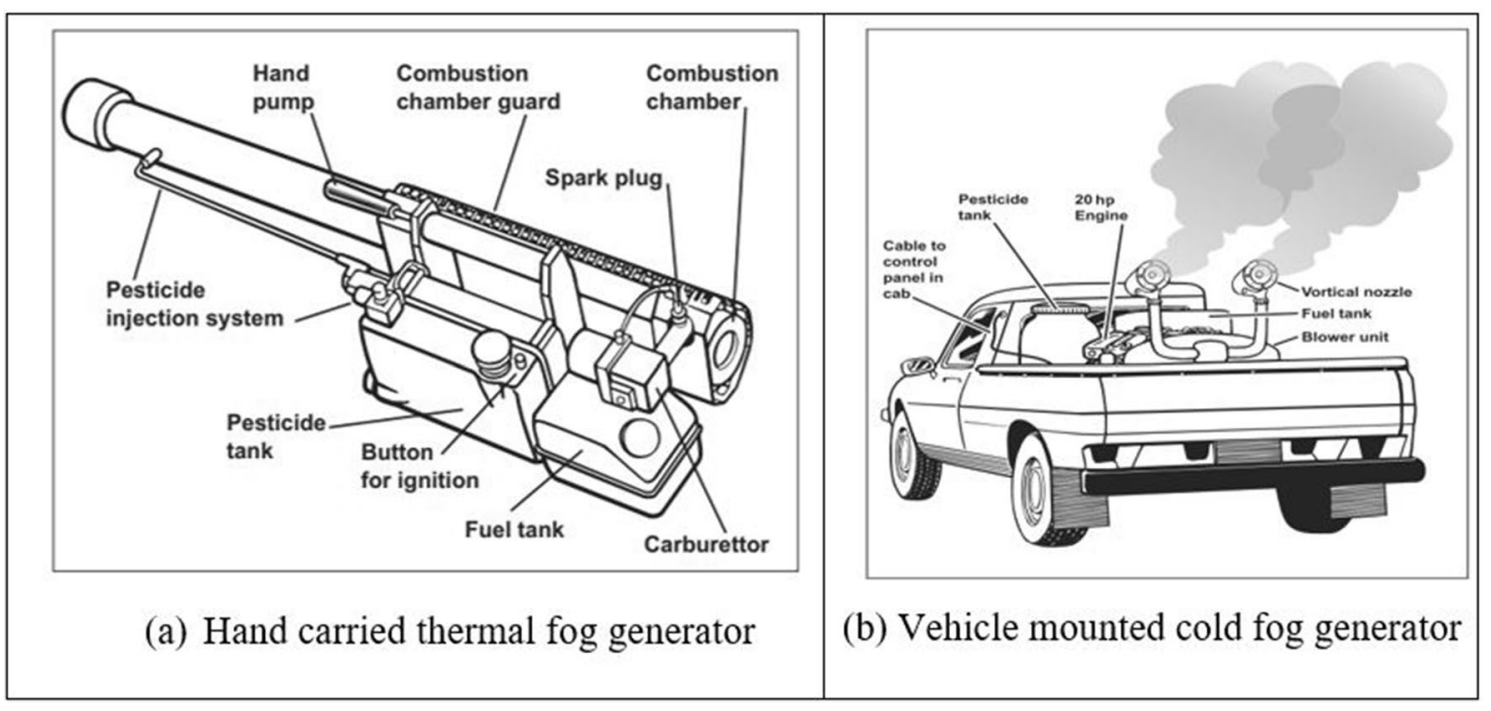

Fig. 4 Type of the fog generator (WHO 2003) 
long passage and disinfectant is sprayed throughout the path. The spray used in the tunnel is sodium hypochlorite solution (Biswal et al. 2020). Defence Research and Development Organisation (DRDO) laboratory developed 'Personalised Sanitization Enclosure' working with mist spray of chemical solution (DRDO 2020). Plast Grup, a Turkish firm modified a hotel shower system into a sanitization device (Dereagzi 2020). The device named Ikarus uses chemical disinfectants, ultraviolet cleaning and has in built body temperature detection unit using thermal camera. A report by Malaysian Health Technology Assessment Section (MaHTAS) under Ministry of Health (Malaysia) tabulates different types of sanitization chamber developed in Turkey, China, Indonesia, Thailand, Malayasia and India (MaHTAS 2020). This report did not find any evidence for the effectiveness of sanitization tunnels. Biswal et al. (2020) warms against developing complacence and avoidance of other difficult and cumbersome modes of sanitization especially due to excessive use of disinfection tunnel.

\section{Object Sanitization}

The genres of sanitization mentioned earlier can be directly and/or indirectly applied for object sanitization. Ultraviolent irradiation and cleaning of surfaces using approved disinfectants are crucial modes of sanitization of objects in domestic and office spaces. Marinella (2020) proposes the use of alcohol wipes to disinfect stethoscopes. Similarly, alcohol based soap/detergent wipes can be used to clean tables, computers and other inanimate objects. Clothes can be sanitized by proper wash. Vegetables and fruits can be sanitized using water, although alcohol based vegetable wash are becoming news too. So far, there is no conclusive proof of their added effectiveness over normal wash of vegetables and fruits using water. As explained in the section on hand washing, rubbing is an effective mode of cleaning due to which the pathogens are dislodged and later soap brings out minimal improvement (Miller et al. 2011). Similarly, vegetables are decontaminated by rubbing properly under running water tap. The process will use the frictional mode of dislodging any contamination and running tap water will remove it from the surface. The drawback is, this process removes any viral trace from the vegetable and fruit peel but does not inactivate it.

\section{Conclusion}

The centrality of sanitization as a means of controlling the spread of pandemic is established when we evaluate the methods of sanitization employed to contain the COVID19 pandemic. The categorisation of sanitization depends on the routes of infection. Three possible routes of infection (i) direct, (ii) indirect and (iii) airborne transmission have been identified as the cause of spread of this pandemic. Individual, object and space sanitization are needed to contain the spread of COVID-19. The end goal of any sanitization process is to remove the virus and inactivate it. Mechanical removal, thermal treatment and chemical disinfection are used in isolation or in combination in the listed categories of sanitization. On an individual level, hand washing and oral hygiene are highly recommended. Hand washing employs rubbing of hands and use of mud, ash, soaps or alcohol based hand sanitizer. Masks have become an inalienable part of attire to stop the spread of virus and sanitization of masks has become a scientific concern. Heat treatment like baking, microwave steam heating; UV irradiation and chemical treatment using vaporised hydrogen peroxide, ozone gas have been recommended. Spaces and objects can be disinfected using mops/wipes, jets and sprays, UVC irradiation, fogging and fumigation. Ventilation and filtering of contaminated air is an important means of sanitizing high-risk zones like hospitals and restaurants.

Since the majority of the processes come with added risks to health due to chemical or radiation overuse, a balanced and non-obsessive sanitization behaviour is recommended. Sanitization based research is a void where technologies and research other than those focused on chemical disinfectants can play a crucial role. Fluid dynamics (Bhardwaj and Agrawal 2020), LEDs (Tseng and Li 2007; McDevitt et al. 2012), surface treatment using carbon nanotubes (Kashyap and Saha 2020), nanocarbons like activated fullerene (Siddiquie et al. 2020) and $\mathrm{TiO}_{2}$ nanoparticles hydrophobic coating (Mahapatra et al. 2020) along with many more strands of science need to focus and contribute to an area as common as sanitization.

\section{References}

Andersen BM, Rasch M, Kvist J, Tollefsen T, Lukkassen R, Sandvik L, Welo A (2009) Floor cleaning: effect on bacteria and organic materials in hospital rooms. J Hosp Infect 71(1):57-65

Anufriev IS, Sharypov OV, Shadrin EY (2013) Flow diagnostics in a vortex furnace by particle image velocimetry. Tech Phys Lett 39(5):466-468

Anuradha P, Devi PY, Prakash MS (1999) Effect of handwashing agents on bacterial contamination. Indian J Pediatr 66(1):7-10

Asadi S, Wexler AS, Cappa CD, Barreda S, Bouvier NM, Ristenpart WD (2019) Aerosol emission and superemission during human speech increase with voice loudness. Sci Rep 9(1):1-10

Asadi S, Bouvier N, Wexler AS, Ristenpart WD (2020) The coronavirus pandemic and aerosols: Does COVID-19 transmit via expiratory particles? Aerosol Sci Technol 54(6):635-638

AYUSH (Ministry of Ayurvedic, Unani, Siddha and Homeopathy) (2020) Ayurveda's immunity boosting measures for self care during COVID 19 crisis. https://www.mohfw.gov.in/pdf/ImmunityBo ostingAYUSHAdvisory.pdf 
Baker KK, Farzana FD, Ferdous F, Ahmed S, Das SK, Faruque ASG, Nasrin D, Kotloff KL, Nataro JP, Kolappaswamy K, Levine MM (2014) Association between moderate-to-severe diarrhea in young children in the global enteric multicenter study (GEMS) and types of handwashing materials used by caretakers in Mirzapur, Bangladesh. Am J Trop Med Hyg 91(1):181-189

Bhardwaj R, Agrawal A (2020) Likelihood of survival of coronavirus in a respiratory droplet deposited on a solid surface. Phys Fluids 32(6):061704

Biswal M, Kanaujia R, Angrup A, Ray P, Singh SM (2020) Disinfection tunnels: potentially counterproductive in the context of a prolonged pandemic of COVID-19. Public Health 183:48

Bloomfield SF, Nath KJ (2009) Use of ash and mud for handwashing in low income communities International Scientific Forum on Home Hygiene (IFH). In: International Scientific Forum on Home Hygiene, Somerset

Bondi CAM, Arbogast JW, Macinga DR, Lambkin-Williams R, Moane E (2007) Virucidal performance of various professional hand hygiene products against avian influenza A H5N1. Am J Infect Control 35(5):E34-E35

Brewer C, Streel E (2020) Is alcohol in hand sanitizers absorbed through the skin or lungs? Implications for disulfiram treatment. Alcohol Alcohol 55(4):354-356

Burfoot D, Hall K, Brown K, Xu Y (1999) Fogging for the disinfection of food processing factories and equipment. Trends Food Sci Technol 10(6-7):205-210

Cadnum JL, Mana TS, Jencson A, Thota P, Kundrapu S, Donskey CJ (2015) Effectiveness of a hydrogen peroxide spray for decontamination of soft surfaces in hospitals. Am J Infect Control 43(12):1357-1359

Cha CN, Park EK, Yoo CY, Jung JY, Son SE, Kim S, Lee HJ (2016) Virucidal efficacy of a paraformaldehyde-containing fumigant against Avian influenza virus. J Prev Vet Med 40(2):68-70

Chamola V, Hassija V, Gupta V, Guizani M (2020) A comprehensive review of the COVID-19 pandemic and the role of IoT, drones, AI, blockchain, and $5 \mathrm{G}$ in managing its impact. IEEE Access 8:90225-90265

Chayaprasert W, Maier DE, Subramanyam B (2010) A simplified and improved modeling approach for the structural fumigation process using computational fluid dynamics. Julius-Kühn-Archiv 425:237

Chen W, Vermaak I, Viljoen A (2013) Camphor-a fumigant during the black death and a coveted fragrant wood in ancient Egypt and Babylon-a review. Molecules 18(5):5434-5454

Chung YK, Lam-Phua SG, Chua YT, Yatiman R (2001) Evaluation of biological and chemical insecticide mixture against Aedes aegypti larvae and adults by thermal fogging in Singapore. Med Vet Entomol 15(3):321-327

Dayrit FM, Newport MT (2020) The Potential of Coconut Oil as an Effective and Safe Antiviral Agent Against the Novel Coronavirus (nCoV-2019)

Dbouk T, Drikakis D (2020) On coughing and airborne droplet transmission to humans. Phys Fluids 32(5):053310

De Sousa A (2020) Disulfiram ethanol reaction in a patient abstinent from alcohol caused by hand sanitizing. Alcohol Alcohol 55(4):349

De Gennes PG, Brochard-Wyart F, Quéré D (2013) Capillarity and wetting phenomena: drops, bubbles, pearls, waves. Springer, Berlin

Dereagzi H (2020) Turkish firm pioneers disinfection against COVID19. https://www.aa.com.tr/en/latest-on-coronavirus-outbreak/ turkish-firm-pioneers-disinfection-against-covid-19/1776693. Accessed 15 June 2020

Diwan SS, Ravichandran S, Govindarajan R, Narasimha R (2020) Understanding transmission dynamics of COVID-19-type infections by direct numerical simulations of cough/sneeze flows. Trans Indian Natnl Acad Eng 5:255-261
DRDO (Defence Research and Development Organisation) (2020). Specification for personal sanitisation enclosure (pse) (vvip version). https://drdo.gov.in/sites/default/files/whats_new_document/ specs_for_VVIP_PSE.pdf. Accessed 15 June 2020

Duguid JP (1946) The size and the duration of air-carriage of respiratory droplets and droplet-nuclei. Epidemiol Infect 44(6):471-479

Emami A, Javanmardi F, Keshavarzi A, Pirbonyeh N (2020) Hidden threat lurking behind the alcohol sanitizers in CoVID-19 outbreak. Derm Ther. https://doi.org/10.1111/dth.13627

FAQ-USEPA (2020) https://www.epa.gov/coronavirus/can-i-use-fumig ation-or-wide-area-spraying-help-control-covid-19. Accessed 11 June 2020

Ghaffari S, Roshanravan N, Tutunchi H, Ostadrahimi A, Pouraghaei M, Kafil B (2020) Oleoylethanolamide, a bioactive lipid amide, as a promising treatment strategy for coronavirus/covid-19. Arch Med Res 51(5):464-467

Han ZY, Weng WG, Huang QY (2013) Characterizations of particle size distribution of the droplets exhaled by sneeze. J R Soc Interface 10(88):20130560

Hilmarsson H, Traustason BS, Kristmundsdóttir T, Thormar H (2007) Virucidal activities of medium-and long-chain fatty alcohols and lipids against respiratory syncytial virus and parainfluenza virus type 2: comparison at different $\mathrm{pH}$ levels. Arch Virol 152(12):2225-2236

Himel CM (1971) New concepts in insecticides for silviculture and old concepts revisited. In: Proceedings of the fourth international agricultural aviation congress (1969), Wagenigen, pp 275-281

Hoffmann WC, Walker TW, Fritz BK, Gwinn T, Smith VL, Szumlas D, Quinn B, Lan Y, Huang Y, Sykes D (2008) Spray characterization of thermal fogging equipment typically used in vector control1. J Am Mosq Control Assoc 24(4):550-559

Hoque BA, Briend A (1991) A comparison of local handwashing agents in Bangladesh. Tropical Med Int Health 94(1):61-64

Huang H, Fan C, Li M, Nie HL, Wang FB, Wang H, Wang R, Xia J, Zheng X, Zuo X, Huang J (2020) COVID-19: a call for physical scientists and engineers. ACS Nano 14(4):3747-3754

Huynh-Delerme C, Artigou C, Bodin L, Tardif R, Charest-Tardif G, Verdier C, Sater N, Ould-Elhkim M, Desmares C (2012) Is ethanol-based hand sanitizer involved in acute pancreatitis after excessive disinfection?-An evaluation with the use of PBPK model. J Toxicol 959070:2012

Ji D, Fan L, Li X, Ramakrishna S (2020) Addressing the worldwide shortages of face masks. BMC Mater 2(1):1-11

Jing JLJ, Pei Yi T, Bose RJ, McCarthy JR, Tharmalingam N, Madheswaran T (2020) Hand sanitizers: a review on formulation aspects, adverse effects, and regulations. Int J Environ Res Public Health 17(9):3326

Kampf G (2018) Antiseptic stewardship for alcohol-based hand rubs. Antiseptic stewardship. Springer, Cham, pp 643-650

Kampf G, Todt D, Pfaender S, Steinmann E (2020) Persistence of coronaviruses on inanimate surfaces and their inactivation with biocidal agents. J Hosp Infect 104(3):246-251

Kashyap U, Saha SK (2020) Enhanced design of PPE based on electrostatic principle to eliminate viruses (SARS-CoV-2). Trans Indian Natl Acad Eng 5:337-341

Kim DK, Kang DH (2018) UVC LED irradiation effectively inactivates aerosolized viruses, bacteria, and fungi in a chamber-type air disinfection system. Appl Environ Microbiol 84(17):e00944-e1018

Kratzel A, Todt D, V'kovski P, Steiner S, Gultom M, Thao TTN, Ebert N, Holwerda M, Steinmann J, Niemeyer D, Dijkman R (2020) Inactivation of severe acute respiratory syndrome Coronavirus 2 by WHO-recommended hand rub formulations and alcohols. Emerg Infect Dis 26:1592-1595

Lal H, Sharma DK, Patralekh MK, Jain VK, Maini L (2020) Out patient department practices in orthopaedics amidst COVID-19: the evolving model. J Clin Orthop Trauma 11(4):700-712 
Lewis MA (1991) Chronic and sublethal toxicities of surfactants to aquatic animals: a review and risk assessment. Water Res 25(1):101-113

Li DF, Cadnum JL, Redmond SN, Jones LD, Pearlmutter B, Haq MF, Donskey CJ (2020) Steam treatment for rapid decontamination of N95 respirators and medical face masks. Am J Infect Control. 48(7):855-857

Li Y, Qian H, Hang J, Chen X, Hong L, Liang P, Li J, Xiao S, Wei J, Liu L, Kang M (2020) Evidence for probable aerosol transmission of SARS-CoV-2 in a poorly ventilated restaurant. medRxiv

Linden PF (1999) The fluid mechanics of natural ventilation. Annu Rev Fluid Mech 31(1):201-238

Liu Y, Ning Z, Chen Y, Guo M, Liu Y, Gali NK, Liu X (2020) Aerodynamic analysis of SARS-CoV-2 in two Wuhan hospitals. Nature $1-4$

Mackenzie D (2020) Reuse of N95 masks. Engineering (Beijing, China)

Mahapatra PS, Chatterjee S, Tiwari MK, Ganguly R, Megaridis CM (2020) Surface treatments to enhance the functionality of PPEs. Trans Indian Natl Acad Eng 5:333-336

MaHTAS (Malaysian Health Technology Assessment Section) Report (2020). Disinfection box/ chamber/ tunnel/booth / partition/ gate on theTransmission of covid-19. Based on available evidence up to 27 April 2020. https://www.moh.gov.my/moh/resources/pener bitan/mymahtas/MaHTAS\%20COVID-19\%20Rapid\%20Evidence /Disinfectant\%20And\%20Sterilisation/Disinfection_Box_Chamb er_Tunnel_Booth_Partition_Gate_To_Reduce_Transmision_ Of_COVID-19_21052020.pdf. Accessed 15 June 2020

Marinella MA (2020) COVID-19 pandemic and the stethoscope: Do not forget to sanitize. Heart Lung J Cardiopulm Acute Care 49(4):350

Mathur P (2011) Hand hygiene: back to the basics of infection control. Indian J Med Res 134(5):611

McDevitt JJ, Rudnick SN, Radonovich LJ (2012) Aerosol susceptibility of influenza virus to UV-C light. Appl Environ Microbiol 78(6):1666-1669

McDonnell G, Bonfield P, Hernandez VD (2007) The safe and effective fumigation of hospital areas with a new fumigation method based on vaporized hydrogen peroxide. Am J Infect Control 35(5):E33-E34

Meszaros JE, Antloga K, Justi C, Plesnicher C, McDonnell G (2005) Area fumigation with hydrogen peroxide vapor. Appl Biosaf 10(2):91-100

Miller T, Patrick D, Ormrod D (2011) Hand decontamination: influence of common variables on hand-washing efficiency. Healthcare Infect 16(1):18-23

Mittal R, Ni R, Seo JH (2020) The flow physics of COVID-19. J Fluid Mech. https://doi.org/10.1017/jfm.2020.330

Miura T, Shibata T (2010) Antiviral effect of chlorine dioxide against influenza virus and its application for infection control. Open Antimicrob Agents J 2(1):71-78

Moore SK (2020) Ultraviolet-LED Maker Demonstrates 30-Second Coronavirus Kill" https://spectrum.ieee.org/tech-talk/semiconduc tors/optoelectronics/ultravioletled-maker-demonstrates-30secondcoronavirus-kill. Accessed 10 June 2020

Novoselac A, Srebric J (2003) Comparison of air exchange efficiency and contaminant removal effectiveness as IAQ indices. Trans Am Soc Heat Refrig Air Cond Eng 109(2):339-349

Ong SWX, Tan YK, Chia PY, Lee TH, Ng OT, Wong MSY, Marimuthu K (2020) Air, surface environmental, and personal protective equipment contamination by severe acute respiratory syndrome coronavirus 2 (SARS-CoV-2) from a symptomatic patient. JAMA 323(16):1610-1612

Panda R, Kundra P, Saigal S, Hirolli D, Padhihari P (2020) COVID19 mask: a modified anatomical face mask. Indian J Anaesth 64(14): 144
Papineni RS, Rosenthal FS (1997) The size distribution of droplets in the exhaled breath of healthy human subjects. J Aerosol Med 10(2):105-116

Park JE, Gallagher T (2017) Lipidation increases antiviral activities of coronavirus fusion-inhibiting peptides. Virology 511:9-18

Pittet D, Allegranzi B, Boyce J, World Health Organization World Alliance for Patient Safety First Global Patient Safety Challenge Core Group of Experts (2009) The World Health Organization guidelines on hand hygiene in health care and their consensus recommendations. Infect Control Hosp Epidemiol 30(7):611-622

Pradhan D, Biswasroy P, Ghosh G, Rath G (2020) A review of current interventions for COVID-19 prevention. Arch Med Res 51(5):363-374

Presser C, Papadopoulos G, Widmann JF (2006) PIV measurements of water mist transport in a homogeneous turbulent flow past an obstacle. Fire Saf J 41(8):580-604

Ray SK, Dobe M, Maji S, Chakrabarty D, Sinha AR, Basu SS (2006) A pilot survey on hand washing among some communities of West Bengal. Indian J Public Health 50(4):225-230

Rose RI (2001) Pesticides and public health: integrated methods of mosquito management. Emerg Infect Dis 7(1):17

Rubio-Romero JC, del Carmen Pardo-Ferreira M, García JAT, CaleroCastro S (2020) Disposable masks: DIsinfection and sterilization for reuse, and non-certified manufacturing, in the face of shortages during the COVID-19 pandemic. Saf Sci 129:104830

Ryu BH, Cho Y, Cho OH, Hong SI, Kim S, Lee S (2020) Environmental contamination of SARS-CoV-2 during the COVID-19 outbreak in South Korea. Am J Infect Control 48(8):875-879

Saini V, Sikri K, Batra SD, Kalra P, Gautam K (2020) Development of a highly effective low-cost vaporized hydrogen peroxide-based method for disinfection of personal protective equipment for their selective reuse during pandemics. Gut Pathogens 12(1):1-11

Schneiderman MT, Cartee DL (2020) Surface disinfection. Infection control in the dental office. Springer, Cham, pp 169-191

Shereen MA, Khan S, Kazmi A, Bashir N, Siddique R (2020) COVID19 infection: origin, transmission, and characteristics of human coronaviruses. J Adv Res 24:91-98

Siddiquie RY, Agrawal A, Joshi SS (2020) Surface alterations to impart antiviral properties to combat COVID-19 transmission. Trans Indian Natl Acad Eng 5:343-347

Singh RK, Tripathi SN (2020) Application of National Aerosol Facility (NAF) in designing of a ventilation system for isolation rooms to minimize interpersonal exposure of sneezing/coughing. Trans Indian Natl Acad Eng 5:263-267

Singla P (2020). Drone technology-game changer to fight against COVID-19. Tathapi with ISSN 2320-0693 is an UGC CARE J 19(6):78-80

Tanaka H, Sakurai M, Ishii K, Matsuzawa Y (2009) Inactivation of influenza virus by ozone gas. IHI Engr Rev 42:108-111

Tang JW, Nicolle AD, Klettner CA, Pantelic J, Wang L, Suhaimi AB, Tan AY, Ong GW, Su R, Sekhar C, Cheong DD (2013) Airflow dynamics of human jets: sneezing and breathing-potential sources of infectious aerosols. PLoS ONE 8(4):e59970

Tseng CC, Li CS (2007) Inactivation of viruses on surfaces by ultraviolet germicidal irradiation. J Occup Environ Hyg 4(6):400-405

Turnbull PCB (ed) (2008) Anthrax in humans and animals. World Health Organization, Geneva

Van Doremalen N, Bushmaker T, Morris DH, Holbrook MG, Gamble A, Williamson BN, Tamin A, Harcourt JL, Thornburg NJ, Gerber SI, Lloyd-Smith JO (2020) Aerosol and surface stability of SARS-CoV-2 as compared with SARS-CoV-1. N Engl J Med 382(16):1564-1567

van Hout R, Rinsky V, Sasson N, Hershcovich C, Tshuva M, Grobman YJ (2018) Axisymmetric jet impingement on a dimpled surface: effect of impingement location on flow field characteristics. Int $\mathrm{J}$ Heat Fluid Flow 74:53-64 
Villafruela JM, Castro F, San José JF, Saint-Martin J (2013) Comparison of air change efficiency, contaminant removal effectiveness and infection risk as IAQ indices in isolation rooms. Energy Build $57: 210-219$

Westwood JC, Mitchell MA, Legacé S (1971) Hospital sanitation: the massive bacterial contamination of the wet mop. Appl Microbiol 21(4):693-697

World Health Organization. (2003) Space spray application of insecticides for vector and public health pest control: a practitioner's guide (No. WHO/CDS/WHOPES/GCDPP/2003.5). World Health Organization, Geneva

World Health Organization (2020a) Modes of transmission of virus causing COVID-19: implications for IPC precaution recommendations: scientific brief, 27 March 2020 (No. WHO/2019-nCoV/Sci_ Brief/Transmission_modes/2020.1). World Health Organization

World Health Organization (2020b) Water, sanitation, hygiene, and waste management for the COVID-19 virus: interim guidance, 23 April 2020 (No. WHO/2019-nCoV/IPC_WASH/2020.3). World Health Organization

World Health Organization (2020c) Modes of transmission of virus causing COVID-19: implications for IPC precaution recommendations: scientific brief, 27 March 2020 (No. WHO/2019-nCoV/
Sci_Brief/Transmission_modes/2020.1). World Health Organization

Xu ZG, Walklate PJ, McLeod AR (1997) Numerical study of a full-size free-air fumigation system. Agric For Meteorol 85(3-4):159-170

Xue Y, Zhang S, Tang M, Zhang T, Wang Y, Hieda Y, Takeshita H (2012) Comparative study on toxic effects induced by oral or intravascular administration of commonly used disinfectants and surfactants in rats. J Appl Toxicol 32(7):480-487

Zonta W, Mauroy A, Farnir F, Thiry E (2016) Virucidal efficacy of a hydrogen peroxide nebulization against murine norovirus and feline calicivirus, two surrogates of human norovirus. Food Environ Virol 8(4):275-282

Zulauf KE, Green AB, Ba ANN, Jagdish T, Reif D, Seeley R, Dale A, Kirby JE (2020) Microwave-generated steam decontamination of N95 respirators utilizing universally accessible materials. mBio 11:e00997-20. https://doi.org/10.1128/mBio.00997-20.

Publisher's Note Springer Nature remains neutral with regard to jurisdictional claims in published maps and institutional affiliations. 